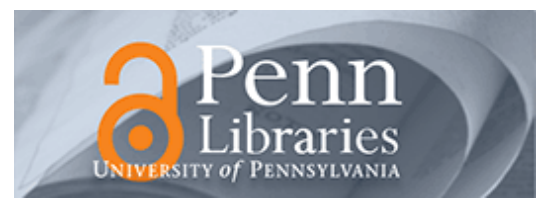

University of Pennsylvania

ScholarlyCommons

\title{
The Cost of Firearm Deaths in the United States: Reduced Life Expectancies and Increased Insurance Costs
}

Jean Lemaire

University of Pennsylvania

Follow this and additional works at: https://repository.upenn.edu/bepp_papers

Part of the Business Commons, Economics Commons, and the Public Affairs, Public Policy and Public Administration Commons

\section{Recommended Citation}

Lemaire, J. (2005). The Cost of Firearm Deaths in the United States: Reduced Life Expectancies and Increased Insurance Costs. The Journal of Risk and Insurance, 72 (3), 359-374. http://dx.doi.org/10.1111/ j.1539-6975.2005.00128.x

This paper is posted at ScholarlyCommons. https://repository.upenn.edu/bepp_papers/14

For more information, please contact repository@pobox.upenn.edu. 


\title{
The Cost of Firearm Deaths in the United States: Reduced Life Expectancies and Increased Insurance Costs
}

\author{
Abstract \\ The United States remains far behind most other affluent countries in terms of life expectancy. One of the \\ possible causes of this life expectancy gap is the widespread availability of firearms and the resulting \\ high number of U.S. firearm fatalities: 10,801 homicides in 2000. The European Union experienced 1,260 \\ homicides, Japan only 22. Using multiple decrement techniques, I show that firearm violence shortens the \\ life of an average American by 104 days ( 151 days for white males, 362 days for black males). Among all \\ fatal injuries, only motor vehicle accidents have a stronger effect. I estimate that the elimination of all \\ firearm deaths in the United States would increase the male life expectancy more than the total \\ eradication of all colon and prostate cancers. My results suggest that the insurance premium increases \\ paid by Americans as a result of firearm violence are probably of the same order of magnitude as the total \\ medical costs due to gunshots or the increased cost of administering the criminal justice system due to \\ gun crime.

\section{Disciplines} \\ Business | Economics | Public Affairs, Public Policy and Public Administration
}


The Cost of Firearm Deaths in the United States:

Reduced Life Expectancies and Increased Insurance Costs

Jean Lemaire

Wharton School

University of Pennsylvania

lemaire@wharton.upenn.edu 


\begin{abstract}
.
The US remains far behind most other affluent countries in terms of life expectancy. One of the possible causes of this life expectancy gap is the widespread availability of firearms and the resulting high number of US firearm fatalities: 10,801 homicides in 2000. The European Union experienced 1,260 homicides, Japan only 22. Using multiple decrement techniques, we show that firearm violence shortens the life of an average American by 104 days (151 days for white males, 362 days for black males). Among all fatal injuries, only motor vehicle accidents have a stronger effect. We estimate that the elimination of all firearm deaths in the US would increase the male life expectancy more than the total eradication of all colon and prostate cancers. Our results suggest that the insurance premium increases paid by Americans as a result of firearm violence are probably of the same order of magnitude as total medical costs due to gunshots or the increased cost of administering the criminal justice system due to gun crime ${ }^{1}$.
\end{abstract}

\footnotetext{
${ }^{1}$ This study was supported by the Firearm \& Injury Center at Penn through a grant from the Joyce Foundation.
} 


\section{Violent Deaths due to Firearms: A US Phenomenon?}

Life expectancy in the US reached a new high of 74.1 years for males and 79.5 years for females in 2000 (National Center for Health Statistics, 2002). However, the US remains far behind most other affluent countries, with US life expectancy ranking $30^{\text {th }}$ for males and $29^{\text {th }}$ for females among the 35 countries and territories that had a Gross Domestic Product per capita, expressed in purchasing power, of at least $\$ 20,000$ in 2000 (author's calculations from Central Intelligence Agency data, 2002). Even within the US, the gap between the life expectancies of Caucasians and African-Americans remains significant: 74.8 years vs. 68.2 years for males, 80.0 vs. 74.9 for females ${ }^{2}$.

The life expectancy at birth $e_{0}^{0}$ is a widely accepted measure of quality of life in a society, summarizing in a single number all the natural and man-made damages that can affect an individual, ranging from poor health care systems and civil war to unhealthy nutrition and sexual behavior. It is commonly used to compare levels of public health among populations, as it summarizes mortality at all ages and is not affected by the age distribution of a population. The potential gain in life expectancy is considered one of the best measures of the impact of eradicating a disease or condition. It is preferable to using the number of years of potential life lost, which is heavily influenced by age structure and total population size and does not account for the effects of competing risks (Lai and Hardy, 1999).

\footnotetext{
${ }^{2}$ Levine et al (2001), noting that there has been no sustained decrease in black/white inequalities in mortality rates since 1945, expect the disparity in life expectancy to either remain stable or increase over the next decade.
} 
Several factors have been proposed to account for the relatively low US life expectancy compared to peer countries, including higher infant mortality, income inequality, and lack of a strong primary care system (Starfield, 2000). The World Health Organization points out that certain population subgroups, such as Native Americans and African-Americans from rural areas and poor urban neighborhoods, live in conditions of poverty similar to those in developing countries (World Health Organization, 2000). It also mentions high levels of violence, especially homicides, in comparison with other industrialized countries. Because the majority of violent deaths in the US is firearmrelated, we believe this aspect of violence warrants further attention. The US is a country that has chosen to live with guns, and now must face the consequences of this choice. While the age-adjusted US firearm homicide rate has decreased by nearly $40 \%$ over the last decade (figure 1), gun violence remains a huge tax on the US quality of life; its rate of firearm fatalities far exceeds that of other industrialized countries.

[Figures 1 and 2 about here]

Figure 2 compares the crude firearm homicide rate per 100,000 inhabitants in countries that have a population in excess of 3.8 million and a GDP per capita, adjusted for purchasing power, in excess of $\$ 20,000$ (World Health Organization, 2002). The US rate dwarfs the rate of any other industrialized country. It is 5.5 times the next highest rate (Italy). Several European countries have a firearm homicide rate that is insignificant: only 45 firearm homicides were reported in the UK, 15 in Denmark, 10 in Norway, 7 in Ireland. While the US experienced 10,801 firearm homicides, the European Union, with 
a total population of over 376 million in 2000, only recorded 1,260 homicides. Only twenty-two firearm homicides occurred in Japan (population: 127 million), a country where it has never been possible for most individuals to acquire a handgun. Less than 50 handguns are present in Japan; they are reserved to athletes participating in international shooting competitions (United Nations on Crime Prevention and Crime Justice, 1999). A comparison of age-adjusted death rates (such as Fingerhut et al, 1998) would provide essentially the same results.

In 2000, 28,663 people in the US died from firearm injury: 16,586 from suicide, 10,801 from homicide, 776 unintentional, 270 from legal intervention, 230 undetermined (Centers for Disease Control and Prevention, 2003). Note that 2000 was only the second year since 1971 that firearm deaths numbered below 30,000³. Table 1 compares the 2000 total number of firearms deaths, firearm homicides, and firearm suicides for all major racial groups, as well as crude rates of death per 100,000 inhabitants. These figures suggest that the widespread availability of guns in the US increases the number of homicides and suicides due to firearms. Cook (1981) estimates that every 10,000 guns sold are involved in about 3,000 robberies and 100 homicides.

\footnotetext{
${ }^{3}$ Figures have unfortunately increased since 2000: 29,573 firearm deaths in 2001 (11,348 homicides), 30,242 in 2002 (11,829 homicides).
} 
Table 1. Firearm deaths and crude rates per race and gender, 2000

\begin{tabular}{||l|r|r|r|r|r|r||}
\hline \multicolumn{1}{|c|}{ RACE AND } & FIREARM & RATE & FIREARM & RATE & FIREARM & RATE \\
\hline White Males & 17,750 & 15.96 & 3,686 & 3.31 & 13,214 & 11.88 \\
\hline White Females & 3,195 & 2.78 & 1,120 & 0.97 & 1,960 & 1.70 \\
\hline Black Males & 6,284 & 37.46 & 5,084 & 30.30 & 965 & 5.75 \\
\hline Black Females & 770 & 4.16 & 615 & 3.32 & 125 & 0.67 \\
\hline Native Males & 196 & 16.25 & 70 & 5.80 & 109 & 9.03 \\
\hline Native Females & 44 & 3.58 & 16 & 1.30 & 24 & 1.95 \\
\hline Asian Males & 352 & 6.46 & 166 & 3.05 & 166 & 3.05 \\
\hline Asian Females & 72 & 1.24 & & & & \\
\hline Total & 28,663 & 10.41 & 10,801 & 3.92 & 16,586 & 6.03 \\
\hline \hline
\end{tabular}

Table 1 suggests that firearm homicide may play a role, alongside many other factors (such as socioeconomic status, unequal access to health care, and a primary health care system that largely ignores disease prevention) in explaining the life expectancy gap between whites and African-Americans. Adjusting for age, African-American males are almost 7 times more likely to die by firearm homicide than white males, a ratio that has changed little in the past 20 years (Levine et al, 2001). 
Firearm homicides disproportionately affect young people: in 2000, the average age at death was 32.4 for white males, 39.3 for white females, 38.2 for black males, and 31.9 for black females (author's calculations from Centers for Disease Control and Prevention data, 2003). In contrast, firearm suicides mostly affect middle-aged white males: whites are nearly twice as likely to die from firearm suicide as African-Americans, and that gap has increased in the past 20 years. In 2000, the average age at death for firearm suicides was 49 for white males, 46 for white females, 36.9 for black males, and 38.4 for black females.

Of course, deaths at early ages have a profound effect on life expectancies. While the discovery of a new drug or procedure slowing down the effect of prostate cancer would only have an insignificant effect on life expectancies, a drastic reduction in firearm deaths would add many years of life to potential victims and possibly lead to a significant improvement in US life expectancies. The purpose of this article is to evaluate the cost of firearm violence in terms of life expectancies. We use actuarial multiple-decrement techniques to estimate the reduction of life expectancy, by race and gender, due to firearm deaths. In other words, we calculate the potential gain in life expectancy that would result from a total elimination of firearm deaths. To put these results into perspective, we also calculate the potential impact of eliminating other major causes of death, such as other fatal injuries and major cancers. We then estimate the fraction of the total premiums for term and whole life insurance due to firearm deaths. 
Many studies attempt to estimate the direct cost of firearm violence in terms of medical treatment (Cook et al, 19994, Cook and Ludwig, 2000). Other costs are more difficult to quantify. They include the cost of public resources devoted to law enforcement, private investment by individuals in protection and avoidance ${ }^{5}$, lost productivity of victims, and changes in the quality of life: limits on freedoms to live or work in certain places, restrictions on residential and commercial location decisions, limitations in hours of operations of retail establishments, emotional costs to the forced adaptation to increased risk, and the cost of pain and fear. Cook and Ludwig (2000), using a willingness-to-pay methodology, estimate the aggregate cost of gun violence in the US at about $\$ 100$ billion annually, or about $\$ 360$ for every American. Other costs yet to be evaluated included the loss of prestige of the US in the international scene or the rejection of the US as a model society to emulate.

This article emphasizes costs that the scientific literature has yet to consider: the increased cost of essential insurance policies, and the cost in terms of life expectancy reduction. Section 2 summarizes the calculation of life expectancies under different scenarios. Results concerning changes in life expectancies are presented in section 3 and discussed in section 4. Section 5 presents changes in life insurance premiums. Section 6 concludes.

\section{Estimation of Life Expectancies}

Multiple decrement life tables, which allow examination of competing causes of death, can be used to calculate life expectancies. Consider a life table

\footnotetext{
${ }^{4}$ Cook et al estimate the mean cost of a firearm injury at about $\$ 17,000$, in 1994 dollars. With about 135,000 fatal and non-fatal injuries per year, the total annual medical cost of gunshot injuries is around $\$ 2.3$ billion, with about half this cost borne by US taxpayers.

${ }^{5} \$ 1,800$ annually per American household, according to one estimate (Anderson, 1999).
} 
$\left\{l_{x}^{(?)}, x ? 0,1,2, \ldots, w\right\}$, where $l_{x}^{(?)}$ is the number of individuals alive at exact age $x . l_{0}^{(?)}$, the radix of the table, is chosen arbitrarily, usually 100,000. $w$ is the last possible age at death. The probability that an individual age $x$ is still alive at age $x+n$ is ${ }_{n} p_{x}^{(?)} ? \frac{l_{x ? n}^{(?)}}{l_{x}^{(?)}}$. The complementary probability that an individual alive at age $x$ has died $n$ years later is ${ }_{n} q_{x}^{(?)} ? 1{ }_{n} p_{x}^{(?)}$. When $n=1$, it is usually omitted: ${ }_{1} q_{x}^{(?)} ? q_{x}^{(?)}$. The complete expectation of life at age $x$, denoted $e_{x}^{0}$, can be calculated as $e_{x}^{0} ? ?_{0}^{?}{ }_{t} p_{x}^{(?)} d t$. It is the expected number of years lived from age $x$.

The annual probability of death $q_{x}^{(?)}$ can be decomposed in two terms: $q_{x}^{(?)} ? q_{x}^{(1)} ? q_{x}^{(2)}$, where $q_{x}^{(1)}$ denotes the probability that an individual age $x$ dies from a firearm injury within a year, while $q_{x}^{(2)}$ is the probability of dying from any other cause. Probabilities $q_{x}^{(1)}$ and $q_{x}^{(2)}$ are called dependent, reflecting the crucial feature of multiple decrement theory that all causes of death interact to produce a society's mortality pattern. The one-year conditional probability of death $q_{x}^{(1)}$ depends not only on firearm injuries but also on all other causes of death. In order to die from a firearm injury, an individual first has to survive all other causes of death up to age $x$. Conditional on this event, $q_{x}^{(1)}$ gives the probability of dying between ages $x$ and $x+1$ due to firearm injury. Paradoxically, an improvement of HIV-related mortality -a disease often prevalent in the same subgroups of society as firearm violence- would actually increase the probability of firearm death.

Annual death probabilities $q_{x}^{(?)}$ for the US population, as well as gender- and race-specific probabilities, are derived from the 2000 US Life Tables (National Center for Health Statistics, 2002). The Injury Mortality Report (Centers for Disease Control and 
Prevention, 2003) provides the number of deaths by cause, age, gender, and race. Annual firearm death probabilities $q_{x}^{(1)}$ for homicides, suicides, and firearm violence, are calculated using census population figures (US Census Bureau, 2003). Dependent probabilities $q_{x}^{(2)}$ are obtained by simple differencing.

The final step in the calculation consists in the calculation of independent or absolute rates of decrement $q_{x}^{\prime(2)}$. These rates describe mortality patterns from which the effects of firearm deaths have been removed. Using either a uniform distribution of deaths assumption, or a constant force of mortality assumption, it can be shown that independent rates can be obtained from the dependent probabilities using the relationship (Bowers et al, 1977)

$$
q_{x}^{\prime(2)} ? 1 ? ? ? q_{x}^{(?)} q^{q_{x}^{(2)} / q_{x}^{(2)}}
$$

Integration of ${ }_{t} p_{x}^{\prime(2)} ? 1 ?{ }_{t} q_{x}^{\prime(2)}$ provides life expectancies at birth $\stackrel{0}{e}_{0}$ when firearm deaths are removed. For a review of the different techniques that have been used by demographers to remove the impact of a particular cause of decrement, see Preston, Heuveline, and Guillot (2001).

\section{Changes in Life Expectancies}

The reduction in life expectancy, in days, due to firearm deaths, for the different groups and causes of death, is found in Table 2. The average American loses 103.6 days of life due to firearm deaths, including 45.9 days lost to homicides and 52.3 days to suicides. The average white male loses five months, the average black male nearly one 
full year. Noteworthy is the huge impact of homicides for black males (nearly 300 days) and suicides for white males (over 100 days).

Table 2. Reduction in life expectancies under different scenarios, in days, 2000

\begin{tabular}{||c|c|c|c||}
\hline POPULATION & $\begin{array}{c}\text { FIREARM } \\
\text { HOMICIDES }\end{array}$ & $\begin{array}{c}\text { FIREARM } \\
\text { SUICIDES }\end{array}$ & $\begin{array}{c}\text { ALL FIREARM } \\
\text { DEATHS }\end{array}$ \\
\hline US & 45.9 & 52.3 & 103.6 \\
\hline US Males & 73.0 & 85.2 & 166.8 \\
\hline US Females & 14.6 & 14.6 & 30.5 \\
\hline White Males & 40.1 & 101.7 & 150.7 \\
\hline White Females & 12.1 & 17.6 & 31.1 \\
\hline Black Males & 296.7 & 50.1 & 361.5 \\
\hline Black Females & 36.0 & 6.8 & 44.6 \\
\hline
\end{tabular}

To place these effects in context, we calculate reductions in life expectancy due to other injuries and cancers in 2000, for an average American, using data from the Centers for Disease Control and Prevention (2003) and the National Cancer Institute (2003). Among all fatal injuries, only motor vehicle crashes, with 160.5 lost days, have a larger effect than firearm violence (Table 3). Life expectancy reductions due to major cancers, as well as the percentage of Americans who die from each cancer, are presented in Table 4. This table provides the increase in life expectancy that would result from a total eradication of the cancer. Cancers reduce the life expectancy of Americans by 2.25 years, with lungs by far the deadliest site. The effect of firearm violence for males, in terms of reduction in life expectancy, is much higher than the combined effect of all colon and prostate cancers. The elimination of all firearm deaths would increase the male life expectancy more than the eradication of all colon and prostate cancers. 
Table 3. Number of deaths and reduction in life expectancy, in days, due to various injuries

\begin{tabular}{||c|r|c||}
\hline INJURY & \# DEATHS & REDUCTION \\
\hline Firearms & 28,663 & 103.6 \\
\hline Motor vehicle accidents & 43,354 & 160.5 \\
\hline Other transportation & 1,413 & 4.9 \\
\hline $\begin{array}{c}\text { Adverse effects of medical } \\
\text { care and drugs }\end{array}$ & 3,059 & 6.3 \\
\hline Drownings & 4,073 & 17.3 \\
\hline Falls & 14,002 & 24.8 \\
\hline Fires & 3,907 & 13.0 \\
\hline Poisoning & 20,230 & 66.4 \\
\hline Suffocation & 12,098 & 38.8 \\
\hline Contacts with object & 1,292 & 4.4 \\
\hline Machinery & 676 & 2.1 \\
\hline
\end{tabular}

Table 4. Life expectancy reduction, in days, due to cancer, and percentage of Americans who die from cancer

\begin{tabular}{||c|c|c||}
\hline CANCER & \% OF DEATHS & REDUCTION \\
\hline All, $\mathrm{M}+\mathrm{F}$ & 21.15 & 821.3 \\
\hline All, $\mathrm{M}$ & 22.87 & 753.9 \\
\hline All, $\mathrm{F}$ & 19.85 & 867.8 \\
\hline Lung, $\mathrm{M}+\mathrm{F}$ & 5.38 & 196.8 \\
\hline Lung, $\mathrm{M}$ & 6.36 & 199.3 \\
\hline Lung, $\mathrm{F}$ & 4.53 & 184.5 \\
\hline Colon, M+F & 2.28 & 66.8 \\
\hline Colon, $\mathrm{M}$ & 2.35 & 63.3 \\
\hline Colon, $\mathrm{F}$ & 2.22 & 68.0 \\
\hline Ovaries, $\mathrm{F}$ & 1.06 & 45.9 \\
\hline Breasts, $\mathrm{F}$ & 3.01 & 144.7 \\
\hline Prostate, $\mathrm{M}$ & 3.12 & 46.5 \\
\hline
\end{tabular}


Note. In gender-specific rows, figures are provided for the particular gender. For instance, the "Ovaries, F" row indicates that $1.06 \%$ of women die from ovarian cancer, and that females on average lose 45.9 days due to that cancer. The percentage of deaths and days lost in the overall population would of course be about $50 \%$ lower.

\section{Discussion}

\section{Firearm deaths partially explain the low US life expectancy}

This study estimates the years of life lost to firearm deaths in the US, and the contribution of these deaths to the gap in life expectancy between the US and other affluent countries. In 2000 , the US male life expectancy was 74.1 years, compared to an average (weighted by population) of 75.8 years in the other 34 richest countries in the world. The US thus suffers from a life expectancy gap of 1.7 years. Our calculations show that 166.8 days or $26.86 \%$ of this gap can be explained by the disproportionate number of US firearm deaths. For females, the US life expectancy of 79.5 years lags 2.56 years behind the average female life expectancy of the other 34 richest countries. Firearm deaths, reducing the life of the average US female by 30.5 days, explain just $3.3 \%$ of the gap.

Within the US, 256.6 days, or $10.6 \%$ of the life expectancy gap between white and black males of 6.6 years is due to firearm homicides. This is consistent with a previous study that found that $14.1 \%$ of the racial disparity in life expectancy for males was attributable to homicide by any means (Potter, 2001). Firearm homicides explain much less of the racial disparity in life expectancy for females, accounting for just $1.3 \%$ 
of the gap. Excess firearm suicides among whites reduce the racial disparity in life expectancy by $2.1 \%$ for males and $0.6 \%$ for females.

\section{Firearm injuries have not been taken into account}

Our calculations consider only firearm deaths and do not account for the increased mortality rate of individuals who survive serious firearm injuries. For example, about 11,000 new cases of spinal cord injury are reported each year, $24.5 \%$ of them the result of violence, primarily gunshot wounds (National Spinal Cord Injury Statistical Center, 2001). The life expectancy of a 20-year old who survived at least one year post spinal cord injury is reduced by 6.3 years in case of paraplegia, 11.3 years in case of low tetraplegia, 15.4 years in case of high tetraplegia, and 25.7 years in case of ventilator dependency. Since these reductions (and comparable ones from other injuries such as severe head trauma) have not been taken into account, the loss in life expectancy attributable to firearms may be slightly underestimated.

\section{Is there a substitution effect?}

Our calculations assume that all firearm deaths are eliminated and not replaced by homicides and suicides by other means. The existence of a substitution effect must be considered. In countries where guns are not readily available, is there a substitution process, where individuals commit suicide and kill each other with other weapons?

In the case of homicides, several international comparisons demonstrate that the substitution effect is minimal or non-existent. Clarke and Mayhew (1988) find that the rate of homicides committed with a handgun in the US is 174.6 times the rate observed in England and Wales. If a substitution effect exists, the rate of homicides committed by 
other means would be much higher in England and Wales. On the contrary, it is 3.7 times higher in the US.

Sloan et al (1988) compare the crime rates in Seattle and Vancouver, two similar cities in terms of population, climate, income per household, poverty and unemployment rates. The only significant demographic difference lies in the racial composition of minorities, with more Asians in Vancouver and more Hispanics and Blacks in Seattle. Gun regulations are much stricter in Vancouver. In Seattle, handguns may be purchased legally for self-defense in the street or at home. After a 30-day waiting period, a permit can be obtained to carry a gun as a concealed weapon. Handguns need not be registered. In Vancouver, self-defense is not considered a valid or legal reason to carry a gun. Concealed weapons are not permitted. The purchase of a gun requires registration and a restricted-weapons permit. Handguns can be transported in a car, but only if stored in a locked box in the trunk. As a result, an estimated $41 \%$ of Seattle inhabitants own a gun compared to only $12 \%$ of Vancouver inhabitants.

The authors find that the two cities essentially experience the same rates of burglary, robbery, homicides and assaults without a gun. However, in Seattle the rate of assault with a firearm is 7 times higher than in Vancouver, and the rate of homicide with a handgun is 4.8 times higher. The authors conclude that the availability of handguns in Seattle increases the assault and homicide rates with a gun, but does not decrease the crime rates without guns, and that restrictive handgun laws reduce the homicide rate in a community.

Killias (1993) uses gun ownership figures obtained through 28,000 telephone interviews in 14 countries: Australia, Canada, the US, and 11 European countries. The 
proportion of homes owning guns varies widely, from $1.9 \%$ in the Netherlands to $48 \%$ in the US, with large variations within the US. The author obtains highly significant Spearman rank correlation coefficients between the percentage of households owning guns and the rate of homicide with a gun (correlation $=0.746$ ), the rate of suicide with a gun (0.900), the overall homicide rate (0.658) and the overall suicide rate (0.515). If a substitution effect exists, the correlations between gun ownership percentages and rates of homicides and suicides by other means than a gun would be significantly negative. They are not (resp. 0.441 and -0.015 , both non-significant). The correlation of 0.441 , although not significant with this small sample, suggests that the number of homicides by means other than a gun increases with raising levels of gun ownership. Thus, the data do not support the existence of a compensation effect for homicides. Similar conclusions were reached by Duggan (2000).

There is some evidence for a substitution effect for suicide. Reduced availability of one method may prompt an increase by other methods (Rich et al, 1990; Sloan et al, 1990; Amos, Appleby and Kiernan, 2001). Some despondent individuals contemplating suicide may attempt to take their life by another means if a firearm is unavailable. Indeed, in countries such as Japan and Hong Kong, suicide rates exceed the US rate despite strictly limited access to firearms. Less than $1 \%$ of suicides in these countries are committed with a firearm (World Health Organization, 2003; Hemenway and Miller, 2000).

A recent study by Shenassa et al (2003) allows an estimation of this substitution effect. The authors study all 10,287 completed suicides and all 37,352 hospital admissions due to attempted suicide recorded in Illinois between 1990 and 1997. Table 5 
provides the percentage of all episodes coded with a particular suicide method, as well as the percentage of fatal cases for each method. Noteworthy is the extreme lethality of firearm suicide attempts. Other techniques are relatively inefficient, due to a significant part on the success of public policy measures such as reductions in the carbon monoxide content of domestic gas, the development of less toxic sleeping pills and antidepressants, and restrictions in the prescription of potentially lethal drugs.

Table 5. Percentage of cases and fatality rate of suicide methods

\begin{tabular}{|c|c|c|c|c||}
\hline \hline METHOD & $\begin{array}{c}\text { \% OF TOTAL, } \\
\text { MALES }\end{array}$ & $\begin{array}{c}\text { \% FATAL, } \\
\text { MALES }\end{array}$ & $\begin{array}{c}\text { \% OF TOTAL, } \\
\text { FEMALES }\end{array}$ & $\begin{array}{c}\text { \% FATAL, } \\
\text { FEMALES }\end{array}$ \\
\hline Firearms & 20.2 & 96.5 & 2.3 & 96.0 \\
\hline Poisons & 58.8 & 11.1 & 87.8 & 3.9 \\
\hline Suffocations & 9.6 & 90.7 & 1.8 & 89.0 \\
\hline Cuts & 6.1 & 9.9 & 4.1 & 2.6 \\
\hline Crash/jumps & 2.2 & 76.1 & 0.8 & 68.8 \\
\hline Exposure & 0.5 & 64.0 & 0.3 & 43.5 \\
\hline Other & 2.5 & 2.4 & 2.9 & 1.4 \\
\hline
\end{tabular}

Note: Poisons: all episodes involving prescription drugs, over-the-counter drugs, and toxic substances such as gasoline and household cleaning substances. Suffocation: episodes involving hanging, strangulation, and suffocation. Cuts: all episodes involving cutting or piercing instruments. Crash/jump: episodes involving crash into a moving object or jump from a high place. Exposure: episodes involving electrocution or exposure to heat or cold.

Excluding firearms, the average fatality rate of all other suicides techniques is $22.42 \%$ for males, $5.99 \%$ for females. We assume that, in the absence of a firearm, suicide candidates select an alternative method in such a way that the relative proportion of each method remains stable. The unavailability of a firearm then would reduce the fatality rate of firearm suicides from $96.5 \%$ to $22.42 \%$ for males, and from $96 \%$ to $5.99 \%$ for females. 
These figures probably overestimate the substitution effect in a significant way. Indeed, they assume that every single firearm suicide attempt is replaced by an attempt using another mean. According to Kleck (1991), firearms are the weapon of choice for suicide attempts because (i) they are extremely lethal; (ii) death by firearm is perceived to be painless; (iii) a gun suicide is easy to carry out with little effort required; (iv) the use of guns require little expertise; (v) a gun suicide is quick, producing death before anyone can intervene; (vi) other methods require a longer preparation time, thus increasing the chances of changing one's mind: (vii) the act of suicide reflects not only desperation, but also a final attempt to be in control of events. Guns allow maximum control over that final act; and (viii) male suicides are often motivated by some loss of effectiveness (loss of a job, a relationship, physical strength,...). The last thing a man wants is another performance failure, hence the choice of a firearm. For all of these reasons, it is likely that the unavailability of a gun would deter at least some suicide candidates from an attempt.

Another reason for the overestimation of the substitution effect is that Shenassa et al only consider suicide attempts that result in death or hospitalization. This overstates the lethality of non-firearm techniques: while nearly every firearm attempt results in a completed suicide or hospitalization, a significant percentage of unsuccessful attempts involving poisons or cuts do not result in hospital treatment. Suicide attempts by other means than firearms are thus undercounted, and their lethality is overstated.

Table 6 revises table 2, by introducing a substitution effect for suicides. It presents the reduction in life expectancy for the various subgroups of the US population, assuming (i) no substitution effect for homicides; and (b) a substitution effect for suicides 
that reduce the lethality of firearm suicides to $22.42 \%$ for males and $6.99 \%$ for females. For an average American, the number of days lost to firearms reduces from 103.6 to 95.8 when the substitution assumptions are inserted in calculations.

Table 6. Reduction in life expectancies under different scenarios, in days, assuming no substitution effect for homicides, and a substitution effect for suicides.

\begin{tabular}{||c|c|c|c||}
\hline POPULATION & $\begin{array}{c}\text { FIREARM } \\
\text { HOMICIDES }\end{array}$ & $\begin{array}{c}\text { FIREARM } \\
\text { SUICIDES }\end{array}$ & $\begin{array}{c}\text { ALL FIREARM } \\
\text { DEATHS }\end{array}$ \\
\hline US & 45.9 & 44.5 & 95.8 \\
\hline US Males & 73.0 & 65.4 & 147.2 \\
\hline US Females & 14.6 & 13.7 & 29.6 \\
\hline White Males & 40.1 & 78.1 & 127.2 \\
\hline White Females & 12.1 & 16.6 & 30.0 \\
\hline Black Males & 296.7 & 38.5 & 350.2 \\
\hline Black Females & 36.0 & 6.4 & 44.2 \\
\hline
\end{tabular}

\section{Changes in Term Life Insurance Premiums}

Firearm deaths increase the cost of life insurance. In this section, the increased price of term and whole life insurance is estimated. Net single premiums are calculated using the population tables, with and without firearm deaths, built in section 2. This calculation overstates the true increased costs of insurance, as the mortality of insured lives is significantly lower that the mortality of the general population. For instance, one study (Metropolitan Life, 1982) suggests a (insured lives suicide rate) / (general population suicide rate) ratio of $56 \%$ for males, $62 \%$ for females. Insured lives are selfselected in the sense that insurance applicants are more likely to be affluent, educated, 
employed, and engaged in a stable relationship, than a person randomly drawn from the general population. More selection due to the insurer's underwriting process eliminates many of the risks most likely to die as a result of firearms. Furthermore, death by suicide is generally not covered during the first two years of a life insurance policy.

Table 7 compares the net single premiums $1,000 A_{25: 20}^{1}$ of a $\$ 1,000,20$-year, discrete term insurance policy on a life age (25) at issue, under the different scenarios: under the current situation, after elimination of all firearm homicides, all firearm suicides, and all firearm deaths. An annual rate of interest of 5\% is used. Table 8 presents the percentage discounts that could be awarded if firearm deaths could be eliminated.

Table 7. Cost of $\$ 1,00020$-year term insurance, age at issue 25 , under different scenarios of elimination of firearm deaths

\begin{tabular}{||c|c|c|c|c||}
\hline \hline POPULATION & CURRENT & $\begin{array}{c}\text { FIREARM } \\
\text { HOMICIDES }\end{array}$ & $\begin{array}{c}\text { FIREARM } \\
\text { SUICIDES }\end{array}$ & $\begin{array}{c}\text { ALL FIREARM } \\
\text { DEATHS }\end{array}$ \\
\hline US & $\$ 17.16$ & $\$ 16.35$ & $\$ 16.37$ & $\$ 15.48$ \\
\hline US Males & $\$ 22.87$ & $\$ 21.53$ & $\$ 21.54$ & $\$ 20.07$ \\
\hline US Females & $\$ 11.48$ & $\$ 11.22$ & $\$ 11.24$ & $\$ 10.97$ \\
\hline White Males & $\$ 20.67$ & $\$ 19.95$ & $\$ 19.07$ & $\$ 18.21$ \\
\hline White Females & $\$ 9.99$ & $\$ 9.79$ & $\$ 9.70$ & $\$ 9.48$ \\
\hline Black Males & $\$ 40.62$ & $\$ 34.19$ & $\$ 39.58$ & $\$ 32.90$ \\
\hline Black Females & $\$ 21.71$ & $\$ 21.00$ & $\$ 21.58$ & $\$ 20.85$ \\
\hline
\end{tabular}

Table 8. Discounts, 20-year term insurance, age at issue 25, under different scenarios of elimination of firearm deaths

\begin{tabular}{||c|c|c|c||}
\hline POPULATION & $\begin{array}{c}\text { FIREARM } \\
\text { HOMICIDES }\end{array}$ & $\begin{array}{c}\text { FIREARM } \\
\text { SUICIDES }\end{array}$ & $\begin{array}{c}\text { ALL FIREARM } \\
\text { DEATHS }\end{array}$ \\
\hline US & $4.69 \%$ & $4.61 \%$ & $9.78 \%$ \\
\hline US Males & $5.88 \%$ & $5.84 \%$ & $12.27 \%$ \\
\hline US Females & $2.20 \%$ & $2.03 \%$ & $4.42 \%$ \\
\hline White Males & $3.48 \%$ & $7.77 \%$ & $11.90 \%$ \\
\hline White Females & $2.03 \%$ & $2.88 \%$ & $5.13 \%$ \\
\hline Black Males & $15.82 \%$ & $2.55 \%$ & $19.00 \%$ \\
\hline
\end{tabular}




\begin{tabular}{||l|l|l|l|}
\hline Black Females & $3.25 \%$ & $0.59 \%$ & $3.97 \%$ \\
\hline
\end{tabular}

Shorter term policies lead to larger discounts. For instance, the discounts to be awarded for a 10-year discrete term policy on a white male life aged 25 at issue, amount to $5.21 \%$ (firearm homicides eliminated), $9.57 \%$ (suicides removed), and $15.68 \%$ (all firearm deaths excluded).

Table 9 compares the net single premiums $1,000 A_{25}$ of a $\$ 1,000,20$-year, fully discrete whole life insurance policy on a life age (25) at issue, under the different scenarios. Table 10 presents the percentage discounts that could be awarded if firearm deaths could be eliminated.

Table 9. Cost of $\$ 1,000$ whole life insurance, age at issue 25 , under different scenarios of elimination of firearm deaths

\begin{tabular}{||c|c|c|c|c||}
\hline POPULATION & CURRENT & $\begin{array}{c}\text { FIREARM } \\
\text { HOMICIDES }\end{array}$ & $\begin{array}{c}\text { FIREARM } \\
\text { SUICIDES }\end{array}$ & $\begin{array}{c}\text { ALL FIREARM } \\
\text { DEATHS }\end{array}$ \\
\hline US & $\$ 98.11$ & $\$ 97.31$ & $\$ 97.12$ & $\$ 96.26$ \\
\hline US Males & $\$ 111.36$ & $\$ 110.08$ & $\$ 109.75$ & $\$ 108.34$ \\
\hline US Females & $\$ 85.32$ & $\$ 85.06$ & $\$ 85.03$ & $\$ 84.75$ \\
\hline White Males & $\$ 107.57$ & $\$ 106.87$ & $\$ 105.66$ & $\$ 104.82$ \\
\hline White Females & $\$ 82.59$ & $\$ 82.37$ & $\$ 82.24$ & $\$ 82.00$ \\
\hline Black Males & $\$ 146.69$ & $\$ 140.94$ & $\$ 145.66$ & $\$ 139.67$ \\
\hline Black Females & $\$ 108.37$ & $\$ 107.69$ & $\$ 108.23$ & $\$ 107.52$ \\
\hline
\end{tabular}

Table 10. Discounts, whole life insurance, age at issue 25, under different scenarios of elimination of firearm deaths

\begin{tabular}{||c|c|c|c||}
\hline \hline POPULATION & $\begin{array}{c}\text { FIREARM } \\
\text { HOMICIDES }\end{array}$ & $\begin{array}{c}\text { FIREARM } \\
\text { SUICIDES }\end{array}$ & $\begin{array}{c}\text { ALL FIREARM } \\
\text { DEATHS }\end{array}$ \\
\hline US & $0.82 \%$ & $1.01 \%$ & $1.89 \%$ \\
\hline US Males & $1.14 \%$ & $1.44 \%$ & $2.71 \%$ \\
\hline US Females & $0.31 \%$ & $0.33 \%$ & $0.67 \%$ \\
\hline White Males & $0.66 \%$ & $1.78 \%$ & $2.56 \%$ \\
\hline White Females & $0.26 \%$ & $0.42 \%$ & $0.71 \%$ \\
\hline
\end{tabular}




\begin{tabular}{||c|c|c|c||}
\hline Black Males & $3.92 \%$ & $0.71 \%$ & $4.78 \%$ \\
\hline Black Females & $0.63 \%$ & $0.13 \%$ & $0.78 \%$ \\
\hline
\end{tabular}

According to the American Council for Life Insurance (2001), there were 148 million group and 35 million individual term life insurance policies in force at the end of 2000. There were 125 million group and 8 million individual whole life policies in force. The total annual premium income was $\$ 31,589$ million in term and $\$ 98,289$ million in whole life. Applying the discounts of $9.78 \%$ for term (table 8 ) and $1.89 \%$ for whole life (table 10) to these total premium volumes provides an estimate of $\$ 4.9$ billion of the insurance cost of firearm violence. This calculation overstates costs, as the mortality of insured lives markedly differ from population mortality. Also, an age at issue of 25 results in high discounts, as homicides mostly affects young adults. Still, this extrapolation suggests that increased insurance costs due to firearms are probably of the same order of magnitude as total medical costs ( $\$ 2$ to $\$ 2.3$ billion, Cook and Ludwig, 2000, Cook et al, 1999) or the increased cost of administering the criminal justice system due to gun deaths, including incarceration costs (\$2.4 billion, Cook and Ludwig, 2000).

\section{Conclusion}

Our findings suggest that the US life expectancy would improve significantly with effective interventions to reduce firearm deaths. These deaths account for $26.86 \%$ of the US males' excess mortality when compared to peer nations, and $8.7 \%$ of the racial gap between black and white males in the US. Although a causal link between the availability of firearms and the rate of firearm deaths has not been proven definitively, a body of US and international studies has consistently shown a strong correlation between 
firearm availability and homicide (Wiebe, 2003; Kellerman et al, 1993; Miller, Azrael and Hemenway, 2002; Cummings et al, 1997). As policymakers seek to reduce racial disparities in life expectancy in the US, and raise US life expectancy to the levels of peer nations, the potential impact of reducing the availability of firearms should be considered. In the US, about $80 \%$ of firearm homicides (and about $70 \%$ of firearm suicides) are committed using a handgun, making this type of firearm a reasonable focus for intervention.

\section{References}

American Council for Life Insurance, 2001, Life Insurance Fact Book 2000 (Washington, DC: ACLI).

Amos T., Louis Appleby, and K. Kiernan, 2001, Changes in Rates of Suicide by Car Exhaust Asphyxiation in England and Wales, Psychological Medicine, 31: 935-939.

Anderson, David A., 1999, The Aggregate Burden of Crime, Journal of Law and Economics, 42: 611-42.

Bowers, Nelson, Hans Gerber, James Hickman, Donald Jones, and Cecil Nesbitt, 1997, Actuarial Mathematics (Schaumburg, IL: Society of Actuaries).

Centers for Disease Control and Prevention, 2003, Web-based Injury Statistics Query and Reporting System, National Center for Injury Prevention and Control (Atlanta, GA: CDC). http://webapp.cdc.gov/sasweb/ncipc/mortrate.html

Central Intelligence Agency, 2002, TheWorld Factbook (Washington, DC: CIA). http://www.cia.gov/cia/publications/factbook/index.html.

Clarke, Ronald, and Pat Mayhew, 1988, The British Gas Suicide Story and its Criminological Implications, Crime Justice, 10: 79-116.

Cook, Philip J., 1981, Guns and Crime: The Power of Long Division, Journal of Policy Analysis and Management, 1: 120-125.

Cook, Philip J., Bruce A. Lawrence, Jens Ludwig, and Ted R. Miller, 1999, The Medical Costs of Gunshot Injuries in the United States, Journal of the American Medical Association, 282: 447-454. 
Cook, Philip J. and Jens Ludwig, 2000, Gun Violence. The Real Costs (Oxford, UK: Oxford University Press).

Cummings Peter, Thomas D. Koepsell, D. Grossman, J. Savarino, and R.S. Thompson, 1997, The Association Between the Purchase of a Handgun and Homicide or Suicide, American Journal of Public Health, 87: 974-978.

Duggan, Mark, 2000, More Guns, More Crime, National Bureau of Economic Research Working Paper 7967 (Cambridge, MA: NBER). http://www.nber.org/papers/w7967.

Fingerhut, Lois A., Christine S. Cox, and Margaret Warner, 1998, International Comparative Analysis of Injury Mortality, Advance Data, Vital and Health Statistics, (Atlanta, GA: Center for Disease Control and Prevention, 303).

Hemenway, David and Matthew Miller, 2000, Firearm Availability and Homicide Rates Across 26 High-income Countries, Journal of Trauma Injury, Infection, and Critical Care, 49: 985-988.

Kellermann Arthur L., Frederick P. Rivara, Norman B. Rushford, Joyce J. Banton, Donald T. Reay, Jerry T. Francisco, Ana B. Locci, Janice Prodzinski, Bela B., Hackman, and Grant Somes, 1993, Gun Ownership as a Risk factor for Homicide in the Home, New England Journal of Medicine, 329: 1084-1091.

Kleck, Gary, 1991, Point Blank. Guns and Violence in America (New York: Aldine de Gruyter).

Killias, Martin, 1993, International Correlations between Gun Ownership and Rates of Homicide and Suicide, Canadian Medical Association Journal, 148: 1721-1725.

Lai, Dejian and Robert J. Hardy, 1999, Potential Gains in Life Expectancy or Years of Potential Life Lost: Impact of Competing Risks of Death, International Journal of Epidemiology, 28: 894-898.

Levine Robert S., James E. Foster, Robert E. Fullilove, Mindy T. Fullilove, Nathaniel C, Briggs, Pamela C. Hull, Baqar A. Husaini, and Charles H. Hennekens, 2001, Blackwhite Inequalities in Mortality and Life Expectancy, 1933-1999: Implications for Healthy People 2010, Public Health Reports, 116: 474-483.

Metropolitan Life, 1982, Recent Trends in Suicide, Statistical Bulletin, 63(4): 2-4.

Miller, Matthew, Deborah Azrael, and David Hemenway, 2002, Rates of Household Firearm Ownership and Homicide Across US regions and States, 1988-1997, American Journal of Public Health, 92: 1988-1993. 
National Cancer Institute, 2003, Surveillance, Epidemiology, and End Results (Bethesda, MD: NCI). http://seer.cancer.gov/faststats/html/dev_prost.html.

National Center for Health Statistics, 2002, United States Life Tables 2000, National Vital Statistics Reports 2000, 51: 3 (Hyattsville, Maryland: NCHC).

National Spinal Cord Injury Statistical Center, 2001, Spinal Cord Injury. Facts and Figures at a Glance (Birmingham, AL: NSCI). http://www.spinalcord.uab.edu.

Potter, Louise, 2001, Influence of Homicide on Racial Disparity in Life Expectancy United States, 1998, Morbidity and Mortality Weekly Report, Center for Diseases Control, 50(36), 780-783 (Atlanta, GA: CDC).

Preston, Samuel H., Patrick Heuveline, and Michel Guillot, 2001, Demography. Measuring and Modeling Population Processes (Oxford, UK: Blackwell Publishers).

Rich Charles L., James G. Young, Richard C. Fowler, John Wagner, and Nancy A. Black, 1990, Guns and Suicides: Possible Effects of Some Specific Legislation, American Journal of Psychiatry, 147: 342-346.

Shenassa, E.D., S.N. Catlin, and S.L. Buka, 2003, Lethality of Firearms Relative to Other Suicide Methods: A Population Based Study, Journal of Epidemiology and Community Health, 57: 120-124.

Sloan John H., Frederick P. Rivara, Donald T. Reay, James A. Ferris, M.R. Path, and Arthur L. Kellermann, 1990, Firearm Regulations and Rates of Suicides. A Comparison of Two Metropolitan areas, New England Journal of Medicine, 322: 369-373.

Sloan, John H, Arthur L. Kellermann, Donald T. Reay, James A. Ferris, Thomas Koepsell, Frederick P. Rivara, Charles Rice, Laurel Gray, and James LoGerfo, 1988, Handgun Regulation, Crime, Assaults, and Homicide. A Tale of Two Cities, New England Journal of Medicine, 319: 1256-1262.

Starfield, Barbara, 2000, Is US Health Really the Best in the World? Journal of the American Medical Association, 284: 483-485.

United Nations on Crime Prevention and Criminal Justice, 1999, United Nations International Study on Firearm Regulations (New York, NY: UN). http://www.uncjin.org/Statistics/firearms

United States Census Bureau, 2003, United States Census 2000 (Washington DC: Census Bureau). http://www.census.gov/main/www/cen2000.html

Wiebe, Douglas, 2003, Homicide and Suicide Risks Associated with Firearms in a Home; A National Case-control Study, Annals of Emergency Medicine, 41: 771-782. 
World Health Organization, 2000, World Health Report 2000 (Geneva, Switzerland: WHO). http://www.who.int/whr2001/2001/archives/2000/en/index.htm.

World Health Organization, 2002, World Report on Violence and Health (Geneva, Switzerland, WHO).

World Health Organization, 2003, Suicides rates (Geneva, Switzerland: WHO). www.who.int/mental_health/prevention/suicide/suiciderates/en/ 